\title{
The Swiss Solvency Test and its Market Implications
}

\author{
Martin Eling, Nadine Gatzert and Hato Schmeiser \\ Institute of Insurance Economics, University of St. Gallen, Kirchlistrasse 2, St. Gallen 9010, Switzerland. \\ E-mails: martin.eling@unisg.ch, nadine.gatzert@unisg.ch, hato.schmeiser@unisg.ch
}

In this paper, we first discuss the characteristics and major benefits of the Swiss risk-based capital standards for insurance companies (Swiss Solvency Test), introduced in 2006. As the insurance industry is one of the largest institutional investors in Switzerland, changes to its asset and liability management as a result of the new regulatory framework could have striking economic effects. Thus, we further examine significant market implications for the Swiss economy due to possible changes in the asset and liability management of Swiss insurance companies. We investigate resulting effects on the Swiss capital market, focusing on bond, real estate, stock, foreign exchange markets, and the situation in case of a capital market crisis. Furthermore, we analyze potential consequences to corporate financing and product design. Most of the considered consequences result from the transition of past (in principle, not risk-based) supervision to risk-based supervision and can thus be generalized to other supervision systems, in particular Solvency II.

The Geneva Papers (2008) 33, 418-439. doi:10.1057/gpp.2008.20

Keywords: risk-based supervision; insurance industry; Swiss Solvency Test; asset management; liability management

\section{Introduction}

Within the last 15 years, most major economies around the globe have changed their regulatory solvency framework to a system of risk-based capital standards. ${ }^{1}$ In Switzerland, risk-based capital standards for insurance companies were introduced in 2006, called the Swiss Solvency Test (SST). The SST is a principle-based, stochastic risk model that includes scenarios for market risk, underwriting risk, and credit risk. As the insurance industry is one of the largest institutional investors in Switzerland, changes in its asset and liability management as implicated by the new regulatory framework could involve considerable market implications for the Swiss economy.

\footnotetext{
${ }^{1}$ Canada and the United States were among the first to introduce risk-based capital standards, in 1992 and 1994, respectively. Japan followed with the Solvency Margin Standard in 1996 and Australia with the General Insurance Reform Act in 2001. Most European countries are relatively slow to develop riskbased capital requirements. The United Kingdom implemented its concept of "enhanced capital requirement" and "individual capital assessment" in 2004 and the Netherlands introduced the "financial assessment framework" in 2006. The European Union is currently working toward harmonization across member countries, one part of which is Solvency II - the implementation of risk-based capital standards in all member countries.
} 
There is a great deal of research that focuses on factors and methodology for predicting solvency ${ }^{2}$ and providing empirical evidence as to the predictability power of solvency models, ${ }^{3}$ but there is very little research that analyzes the economic implications of equity capital regulation on the associated capital markets and economies. Some existing research does address the economic effects of regulation on the insurance market itself. Munch and $\mathrm{Smallow}^{4}$ find that minimum capital requirements reduce the number of insolvencies by reducing the number of small firms. Van Rossum ${ }^{5}$ points out the positive connection between the degree of regulation and its costs; furthermore, the author highlights the pressure regulation exerts on small insurers specialized in certain products and niches. Cummins and Rubio-Misas $^{6}$ use frontier efficiency analysis to find improved efficiency and consolidation in the Spanish insurance industry following its deregulation in the 1990s.

In this paper, we first present the main characteristics of the SST and briefly compare the SST approach to other regulatory systems, such as the U.S. risk-based capital standards or the European Union's Solvency II framework. Second, we investigate the SST's major economic implications due to altered asset and liability management, based on the study by Schmeiser et al. (2006). We focus on resultant effects on the Swiss capital market concerning bond, real estate, stock, foreign exchange markets, and the situation in case of a capital market crisis. Moreover, we study potential consequences to corporate financing and product design. These effects can be generalized to other manifestations of supervision, since they are primarily caused by the transition to risk-based supervision. This is of particular interest for the Solvency II regulations planned for the European Union.

The remainder of this paper is structured as follows. After a brief description of the SST in the following section, we analyze the influence of the SST on the asset management of Swiss insurance companies in the next section. The penultimate section focuses on the underwriting side, corporate finance, and the impact of the SST on product design. The final section concludes.

\section{The SST: An overview}

The SST was developed by the Swiss Federal Office of Private Insurance (FOPI) in cooperation with the Swiss insurance industry. Even though it was implemented in 2006, prior to Solvency II, compatibility between the two was one of the SST's objectives. ${ }^{7}$ Under the SST market, credit, and insurance risks are quantified by standardized factor models, whereas other risk categories (e.g., catastrophe risk) are covered by scenario analysis. The modular structure of the SST is shown in Figure 1.

\footnotetext{
${ }^{2}$ See Brockett et al. (1994); Carson and Hoyt (1995); Browne et al. (1999); Baranoff et al. (1999); Chen and Wong (2004).

${ }^{3}$ See Cummins et al. (1995, 1999); Grace et al. (1998); Pottier and Sommer (2002).

${ }^{4}$ Munch and Smallwood (1981).

${ }^{5}$ Van Rossum (2005).

${ }^{6}$ Cummins and Rubio-Misas (2006).

${ }^{7}$ See Federal Office of Private Insurance (2004).
} 


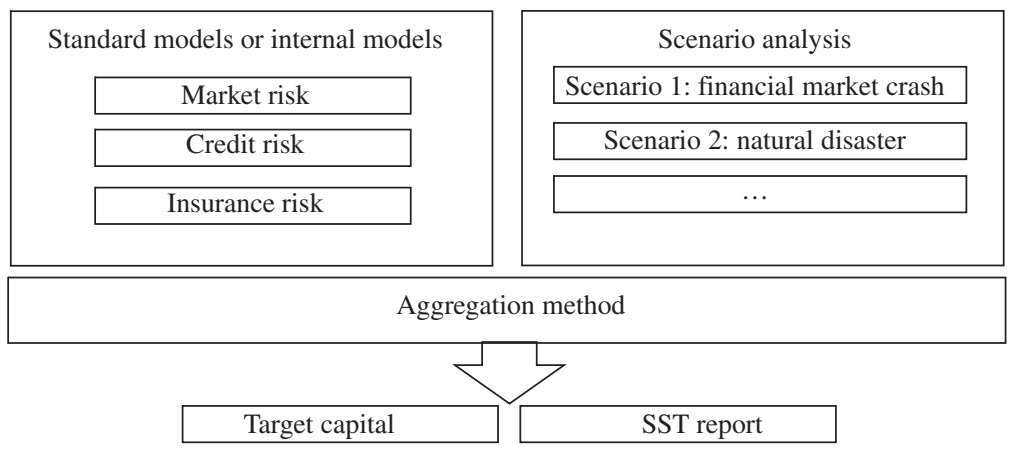

Figure 1. Structure of the SST (Federal Office of Private Insurance, 2004, p. 10).

To determine the target capital, the results of the standard models are aggregated with the results of the scenario analysis, during which diversification effects are taken into account. In addition to this aggregation, a report is generated that summarizes the insurer's exposure in regard to the different risk categories. As in Solvency II, it is also possible to use internal risk models instead of standard models. ${ }^{8}$

The market risk model takes into consideration changes in interest rates, stock prices, currencies, or real estate prices. It is based on the risk metrics model developed by J.P. Morgan, which is the most widespread approach for calculating value at risk in the banking industry. The risk factors are multivariate normally distributed and aggregated using a variance-covariance approach. The regulator estimates these risks by using 10 years of monthly returns of selected market indices. However, not all parameters are determined by the regulator but should rather be estimated by the insurer based on its portfolio. This practice emphasizes the principle-based approach of the SST compared to a rules-based approach (see, e.g., Solvency I).

The credit risk standard model is the same approach as used in Basel II. However, in contrast to Basel II, operational risks are not integrated into the model, but are instead considered on a qualitative basis within the SST report. Applying the Basel II credit risk approach within the SST framework has the advantage of being easy to implement and also reduces the incentives for regulatory arbitrage between the banking and insurance industry.

Insurance risk is modeled separately for life, non-life, and health insurance. There is no standard model for reinsurers since they are expected to have adequate internal risk models for calculating insurance risk.

- In the life insurance context, the standard model consists of seven risk factors, including, for example, mortality, lapse rate, and exercise of product options. All risks are modeled using a normal distribution and are aggregated under given assumptions on correlations between these risks.

\footnotetext{
${ }^{8}$ The pros and cons of the use of internal versus standard models are discussed in detail in Eling et al. (2007, pp. 79-80) in the context of Solvency II.
} 
- In the non-life insurance context, risk is subdivided into three groups: small claims, large claims, and change in provisions (resulting from the previous year's claims). Furthermore, catastrophe risks are included as part of the scenario analysis. The sum of the small claims is modeled using a normal distribution, while the number and size of large claims are modeled separately. The number of claims is Poisson distributed, and each line of business has an individual distribution, for example a Pareto distribution, with given parameters for the claim size. For changes in provisions, the SST uses a shifted inverse lognormal random variable with a mean of zero and a predefined variance. ${ }^{9}$

- The standard model for health insurers assumes that insurance risk is independent of financial market risk. The model considers three health insurance lines: nursing expenses, individual per diem allowance, and collective per diem allowance. For each of these three lines, mean and standard deviation are estimated on the basis of historical data. The lines are then aggregated using assumptions on the correlations between the cash flows of the different lines. ${ }^{10}$

Risks not accounted for by these standard models are covered by quantitative and qualitative scenarios. Qualitative scenarios are included in the SST report; quantitative scenarios are considered when calculating the target capital. Among the quantitative scenarios are, for example, natural disasters or a financial market crash. For these scenarios, a probability of occurrence and the resulting effect on the solvency level are estimated.

Similar to Solvency II, determination of the target capital follows a two-level approach. The first level is a standard rules-based minimum capital - the so-called safety net - based on the Solvency I rules used in European Union. The second level is a required target capital (or solvency capital), which is defined as the amount of capital needed at time zero to meet future obligations (the assumed risk) over a fixed time horizon for a required safety level $\alpha$. Under the SST, the insurer's available economic capital is called "risk-bearing capital" $(R B C)$ and represents the ability to bear the assumed risk. It is defined as the difference between assets and liabilities.

The transformation from the statutory balance sheet to the market-value-based approach at $t=0$ is shown in Figure 2.

The random variable $X_{1}$ used to calculate the target capital is defined by means of the change of $R B C$ within 1 year (the risk-free interest rate $r$ is provided by the regulator): ${ }^{11}$

$$
X_{1}=\frac{1}{1+r} R B C_{1}-R B C_{0} .
$$

For scenario analyses, the available capital $\mathrm{RBC}$ is generally reduced compared to "normal" years. The distribution of $R B C_{1}\left(=A_{1}-L_{1}\right)$ is based on the distribution of

\footnotetext{
${ }^{9}$ See Luder (2005).

${ }^{10}$ See Federal Office of Private Insurance (2004).

11 Ibid.
} 


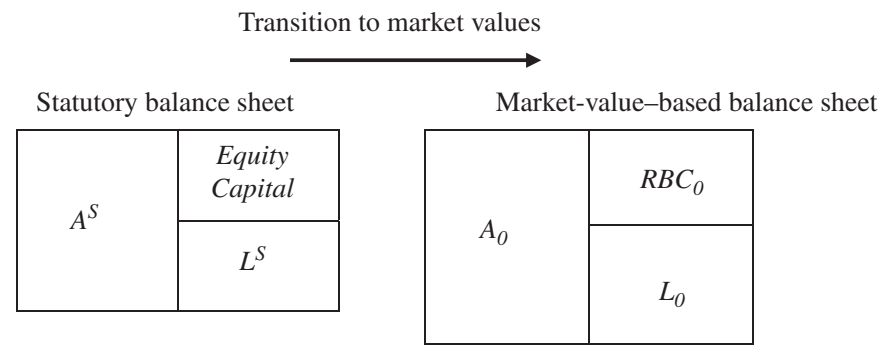

Figure 2. Balance sheet transformation at $t=0$. Notes: $A^{S}, L^{S}=$ statutory value of assets and liabilities at $t=0 ; A_{0}=$ market value of assets at $t=0 ; L_{0}=$ best estimate of liabilities at $t=0 ; R B C_{0}=$ risk-bearing capital at $t=0$.

the assets and liabilities in $t=1$ and will be estimated from historical data. The expected shortfall $(E S)$ is defined as

$$
E S_{\alpha}=-E\left(X_{1} \mid X_{1} \leqslant \operatorname{VaR} R_{\alpha}\right)
$$

where $V a R_{\alpha}$ denotes the value at risk for a confidence level $\alpha=1$ percent, given by the quantile of the distribution $F^{-1}(\alpha)=\inf \{x: F(x) \geqslant \alpha\}$ (see Figure 3).

The target capital is given by

$$
T C_{\alpha}=E S_{\alpha}+M V M,
$$

where $M V M$ stands for the market value margin, which is defined as the discounted run-off costs (in case of an insolvency). The distribution function of $X_{1}$ used to determine the target capital is obtained by aggregating the distribution functions of normal years with the distribution functions of the scenarios. This is done by weighting the functions with the assumed probability of occurrence.

Regulators expect the insurer's target capital not to exceed the available economic capital in $t=0$, i.e.,

$$
R B C_{0}=A_{0}-L_{0} T C_{\alpha}
$$

Enforcement of these amounts under the SST is somewhat vague and still under construction. Current planning is going in the direction of Solvency II. There will be different intervention levels depending on the relation of available capital to target capital. Falling below the minimum capital will result in the imposition of sanctions. However, contravention of the target capital so far leads only to discussions between the supervisor and the insurer.

The SST follows a principle-based approach instead of using a rules-based approach as implemented, for example, in the U.S. risk-based capital standards. A major drawback of standard rules-based models is that these have no flexibility to handle individual situations and thus might not be very effective in assessing the wide range of insurance risk profiles. The principle-based approach is flexible and captures the individual risk profile, for example, by using parameters of the insurer instead of those predetermined by the regulator. A principle-based approach also might trigger 


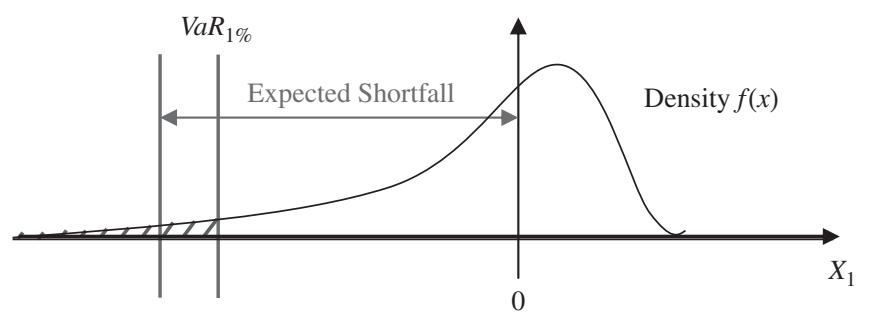

Figure 3. Determination of target capital using the expected shortfall concept.

innovation when insurers need to develop their own risk models based on the principles. Furthermore, the principle-based approach provides the insurer with the opportunity to integrate regulatory requirements into its risk management process. Business and regulatory objectives then go hand in hand and lead to a more efficient regulation and risk management. ${ }^{12}$ Another advantage of using principles instead of strict rules is that this might reduce the danger of systematic behavior and, in turn, systemic risk (see the sub-section below on the effects of the capital market crisis for a detailed discussion). But these advantages do not come without drawbacks. Relying upon principles might increase the complexity and costs of regulation, both for the insurer, who needs time and money to implement the principles into a model, and for the regulator, who needs sufficient resources to control all the individual models instead of one standard model.

Regarding the risk measure used, the expected shortfall concept in the SST allows - in contrast to the value-at-risk approach - to capture the actual extent of a shortfall. The latter is anticipated in the Solvency II project, even though it is a controversial concept based on the ruin probability approach. The advantage of the value at risk is its easier implementation as it does not require data to estimate the tail of a distribution, which - at the same time - represents its most serious drawback: The debate in the literature about the adequacy of risk measures for solvency measurement especially stresses the fact that the value at risk only takes into account the number of shortfalls. In contrast to the expected shortfall, the value at risk does not provide information about the severity of the default. Hence, it may be adequate from the shareholders' perspective in the case of limited liability where losses are restricted to the initial payment. However, the cost of insolvency is significant for policyholders and will thus also be of central concern for regulators. In addition, the expected shortfall is especially suitable for risks with low frequency and high severity. ${ }^{13} \mathrm{~A}$ further discussion of advantages of risk measures can also be found in, for example, Barth ${ }^{14}$ and Butsic. ${ }^{15}$

\footnotetext{
12 See Financial Services Authority (2007).

${ }^{13}$ See European Actuarial Consultative Group (2004).

14 Barth (2000).

15 Butsic (1994).
} 
The target capital is derived based on market-consistent values of assets and liabilities, and thus ensures a realistic picture of an insurer's risk capacity. This is different from the U.S. framework, which uses balance sheet items for target capital calculations. A market-consistent valuation of risk requires the implementation of sound financial methods (e.g., option pricing methods) that can account for relevant sources of uncertainty in cash flows. Thus, the SST supports the employment of modern financial tools in the risk management processes of insurance companies, which is further enhanced by the possibility of using internal models in place of the standard models. This is an important advantage compared to the U.S. system, which permits standard factor models only. These issues are also reflected in positive feedback from market participants after the SST field test in 2005. ${ }^{16}$ In particular, participants found internal risk models to be excellent management tools and - due to a more efficient use of capital - as a potential competitive advantage. Furthermore, the increased transparency is seen as an important factor for revealing financial strengths and weaknesses. It is also expected to reduce the whole insurance sector's cost of capital and to prevent insolvencies due to a transition towards a more riskaware culture. Overall, the SST can be characterized as a modern and progressive regulatory framework that could serve as the basis for further developments in the European Union.

\section{Effects of risk-based capital standards on asset management}

\section{Effects on bond markets}

\section{The yield curve}

In the past, regulators merely defined upper limits for investments in each asset class. The SST, in contrast, requires an adequate amount of solvency capital for the assumed investment risk. This creates a natural incentive for insurers to assume fewer risks by, for example, decreasing the portfolio amount invested in risky assets and/or by increasing the amount invested in relatively safe assets such as high-rated bonds.

The SST also promotes reducing the duration mismatch between assets and liabilities, which can lead to an increase in the demand for long-term bonds and trigger capital shift, particularly in the life insurance business. Such shifts in demand were observed in the United Kingdom, where the term premium has been negative during the last several years. Higher minimum capital requirements (the "enhanced capital requirements" and "individual capital assessment") ${ }^{17}$ and the introduction of the accounting standard FRS 17 led to large purchases of long-term bonds by U.K. insurance companies and pension funds. ${ }^{18}$ Furthermore, discussions with respect to "liability-driven investment" strategies are already occurring in practice, having as a goal the congruent organization of assets and liabilities. ${ }^{19}$ Implementing such

\footnotetext{
${ }^{16}$ See Federal Office of Private Insurance (2006c).

${ }^{17}$ See Sandström (2006, pp. 159-166).

${ }^{18}$ See Bank for International Settlements (2006, p. 102).

${ }^{19}$ See Huesler (2006, p. 24).
} 
strategies could at least in the short term lead to disequilibrium on the rather small Swiss bond market. Long-term bonds might then exhibit abnormally low interest rates and we might observe similar effects as have occurred in the United Kingdom.

To substantiate the actual potential of the underlying problem, we compare volumes of invested capital and market capitalization. The private Swiss insurance industry currently invests CHF 511 billion worldwide, of which CHF 206 billion is invested in bonds. ${ }^{20}$ According to the Swiss stock exchange, the market capitalization of Swiss bonds at the end of the year 2005 amounted to CHF 256 billion, ${ }^{21}$ which shows that the Swiss capital market is indeed very small for Swiss insurance companies. Hence, the suggested effects could actually occur, leading to a higher demand for long-term bonds. According to analysts, such a demand surplus could exist for $10-15$ years. ${ }^{22}$ In the case of unchanged supply, prices of long-term bonds would rise and, in turn, interest rates fall, leading to a flat yield curve. However, attractive prices will motivate bond issuers to expand the supply. This additional supply will need to come mainly from sovereign institutions due to the necessity of low counterparty risk. Furthermore, other long-term investments can be used as substitutes, such as mortgages, assetbacked securities, or long-term corporate bonds.

At present, a clear trend toward an expansion of long-term bond volume in the international capital markets can be observed. France and Great Britain, for example, have already exploited the attractive issuing conditions of long-term bonds and issued new government bonds with a 50-year maturity. The key argument for very long maturities is that the government can secure the currently low interest rate for a long period. $^{23}$

\section{The quality spread}

Along with the shift in the yield curve, the introduction of risk-based capital standards might also influence the quality spread, which is the difference in yields between "good"-rated borrowers and "bad"-rated borrowers. Since important parts of the SST capital requirements are built on ratings, bond issuers of bad-rated (or not-rated) companies might have to pay higher interest rates in the future.

In this context, the Basel II experience - the equity capital regulations in the banking industry - is highly relevant. It is frequently stated that bad- or not-rated companies have had to pay higher interest rates since the introduction of Basel II, ${ }^{24}$ which - especially for smaller companies - has led to increasing refinancing costs in the past several years.

Considering the quality spread, the SST capital requirements can lead to a situation where insurers reduce their investment risks in order to lower their capital

\footnotetext{
${ }^{20}$ See Swiss Insurance Association (2006, p. 9).

${ }^{21}$ For the statistics, see www.swx.com. The volume number represents all bonds issued in CHF by Swiss companies at the SWX Swiss Exchange. There are also foreign bond issuers, but their bonds are partially issued in $\mathrm{CHF}$ and partially in foreign currencies.

${ }^{22}$ See Huesler (2006); Miles and Baker (2005).

${ }^{23}$ See Reitz and Stocker (2005, p. 37).

${ }^{24}$ See, for example, Grunert et al. (2002, p. 1045ff.).
} 
requirements. Transferring these considerations to credit qualities implies that the portion invested in relatively safe bonds, such as government bonds, will increase, while the portion invested in riskier bonds, such as distressed corporate bonds, will decrease. In this environment, demand for bad- or not-rated bonds might decline.

Hence, in contrast to Solvency I, ratings are essential in the SST, for example for deriving the credit risk of the insurer's bond portfolio and for determining the default risk of the reinsurance exposure. Empirical evidence shows that rating agencies have been relatively successful in identifying financial distress, for example, compared to regulators. ${ }^{25}$ However, insurers and regulators should be aware of substituting their own due diligence by ratings since the rating agencies' methodologies are not really transparent.

\section{Effects on real estate markets}

Tendencies similar to those of the bond market can be expected for commercial and residential real estate. In this context, there is current controversy in the Swiss insurance market as to whether real estate exhibits duration. This is an essential question for Swiss insurers because they intend to use real estate for duration matching in order to lower their capital requirements. The answer to this question and the consideration of such duration in the SST might thus affect the investment policy of insurers over the next few years. If real estate cannot be used for duration matching, the attractiveness of real estate is reduced.

This is particularly true for commercial real estate, which exhibits a high volatility of approximately 11 percent per annum, measured on the basis of the WUPIX A, an index for listed real estate companies. ${ }^{26}$ In contrast, residential real estate has a much lower volatility of approximately 4 percent per annum (computed on the basis of the IAZI, an index for Swiss residential real estate), and thus cannot be considered a risk driver within the standard model. A possible shift in the demand for real estate investment (if it cannot be used for duration matching within the SST) can then affect the market prices of both commercial and residential real estate. To shed some light on the impact of potential shifts, we consider the size of the real estate market. Of the CHF 511 billion invested by insurers at the end of 2005, CHF 64.6 billion were invested in real estate and mortgages. ${ }^{27} \mathrm{An}$ indicator for the size of the Swiss real estate market is the Swiss property benchmark, which presently comprises CHF 62 billion, ${ }^{28}$ including 50-60 percent of all large Swiss real estate portfolios. We thus have to assume that the Swiss insurance industry holds a significant portion of the institutional real estate market.

\footnotetext{
${ }^{25}$ See Pottier and Sommer (2002).

${ }^{26}$ Note that it is also possible for insurers to calculate the capital requirements for commercial real estate using their own volatilities and correlations. It is only when the insurer does not use its own data that the values of the WUPIX A are consulted.

${ }^{27}$ See Swiss Insurance Association (2006, p. 9). We again point out that this amount is not completely invested in the Swiss capital market, but also in foreign capital markets.

${ }^{28}$ See Informations- und Ausbildungszentrum für Immobilien (2006, p. 2). Note that investment in mortgages is not part of the Swiss property benchmark.
} 
This comparison clarifies that the Swiss capital market could be - similar to the bond market - too small and that the previously discussed market implications might indeed occur. However, other characteristics of the SST may dampen these effects, including, for example, the SST's emphasis on diversification. Therefore, real estate will also serve as a diversification element in insurers' portfolios in the future. However, if there is less demand and unchanged supply in the real estate market, real estate prices will still fall. In contrast to the bond market, there is no quick fix for the real estate market (at least in the short to medium term), since a reduction of supply is not realizable in the short term. A decrease in house-building activity and thus of the real estate supply is possible, but only in the very long term.

It could be hypothesized that other investors will be attracted by low real estate prices and therefore effect an adjustment in demand. But since the supply side of the real estate market is clearly less flexible than is bond market supply, we expect stronger effects in the real estate market than in the bond market. We also expect lower real estate prices in the future if insurance companies reduce their demand for real estate investment.

\section{Effects on stock markets}

The total investment volume in stocks by Swiss insurers is rather small. According to current data from the FOPI, ${ }^{29}$ life insurers' investment in stocks is on average 10.14 percent; property-liability insurers invest 7.53 percent.

It must be emphasized that the SST primarily focuses on the risk of an investment, and pays far less attention to return potential. Return on investments is considered in the SST standard model for property-liability insurers, but not for life insurers. For life insurance, integration of the return potential is possible only when an appropriate internal model is used. Motivated by the SST, insurers might generally prefer to select less risky investment strategies, but this would also mean that they will not offer their customers products with a high return potential because these products require too much regulatory equity capital.

This emphasis on relatively safe investment strategies could be a significant competitive disadvantage, especially compared to pension funds, which have no comparable equity capital requirements. Insurers may offer only products with relatively low risks and small returns, whereas pension funds are able to offer not only low-risk products but also riskier products with higher return potential. This is a disadvantage for insurers in the market for private retirement arrangement products, as young consumers with a long-term investment horizon might prefer to buy riskier products. Thus, the most important customer group in the market for private retirement arrangement products is not accessible to the insurers. The only exception is unit-linked life insurance products, which do allow riskier investment strategies.

Looking at the low percentage of stocks in insurers' investment portfolios might lead one to believe that insurers anticipated the introduction of the SST and that some or most of the capital shifting might have already occurred within the last few years.

\footnotetext{
${ }^{29}$ Federal Office of Private Insurance (2006a).
} 
The portion of stocks and investment fund shares went from 17.36 to 7.92 percent in the period between 1999 and $2005 .^{30}$ One main driver of this development was the stock market plunge that occurred from 2000 to 2003, but another impetus could well have been anticipation of the SST. The reduction of investment in real estate as well as the increase in relatively safe investments, such as fixed-income securities, might provide some additional support for this hypothesis. ${ }^{31}$ In summary, we conclude that there will not be much change in the stock investment behavior of Swiss insurers due to the SST.

\section{Effects on foreign exchange markets}

The discussion so far suggests that the Swiss capital market is not of sufficient volume for Swiss insurance companies. In particular, in regard to long-term bond markets, the expected increase in demand cannot be met by the existing supply. Therefore, longterm bond prices might rise. Alternatively, or in addition, investment in the foreign currency area might increase. Owing to its large volume, the euro area in particular would offer an alternative; the gross sales volume of euro bonds in the year 2005 amounted to US\$ $1,796.7$ billion. ${ }^{32}$ Increased purchases by Swiss insurance companies thus might not have much effect on prices in this market.

In contrast to the Swiss capital market, however, investing in the foreign currency area entails additional currency risk, which, in practice, is typically eliminated by hedging on a rolling basis. However, substantial residual risks, especially crosscurrency risks, remain for insurers even when they engage in hedging. Since bonds are bought on a long-term basis and currency hedging is mostly conducted on a threemonth basis, future hedging costs are uncertain.

Therefore, the introduction of the SST might lead to expanded investment in foreign countries with consequent possibly substantial additional risk. However, the SST quantifies currency risks, which are thus transparent over exchange rates. Additional foreign exchange risk will therefore also result in an appropriate increase of required capital. Moreover, it is important to note that while currency risk certainly might involve a negative deviation from the expected result, it can also result in a positive deviation from the expected value. Increased investment in the foreign currency area also results in increased diversification. However, hedging practices could very well lead to substantial costs.

Previously, currency risks were limited by congruence requirements in asset regulation. The current asset guidelines, effective 12 June 2006, also contain a congruence requirement. However, this rule is void if the SST is met. As mentioned, currency risks are appropriately taken into consideration in the SST market risk model. Therefore, an additional commitment in the foreign currency area will lead to an increase of the capital requirements. If, however, the foreign bond market still

\footnotetext{
${ }^{30}$ The data can be found at http://www.versicherungsmarktbpv.admin.ch. Note that the numbers presented here are aggregated over all insurers (life, property-liability, and reinsurance).

31 Other drivers might have been the increasingly risk-based evaluation of rating agencies or the increasing use of risk-based capital allocation models in the insurance industry.

${ }^{32}$ See Bank for International Settlements (2006, p. 28).
} 
appears attractive, insurance companies will increase their investment in it, which implies that they are also willing to bear the additional foreign exchange risk and the transaction costs resulting from hedging. All these effects will be adequately reported in the SST market risk model.

\section{Effects in capital market crisis}

The SST provides the opportunity for insurers to use internal, instead of standard, risk models to determine capital requirements. An internal model is one constructed by the insurer for its specific needs. A standard model is designed by the regulator and used uniformly across insurers. For example, the market risk model of the SST is the standard model approach for calculating market risk. Under certain circumstances, such a standard model might contain some systematic risk. With a standard model, an unusual event in the capital or insurance market could result in an identical response by all insurers, thereby causing a run on the market. ${ }^{33}$ The 2001 response to capital market shifts is an example. Following the plunge in stock market prices, many insurers started to shift their asset allocation from stocks to bonds, which led to a further expansion of the stock supply and thus to a further plunge. ${ }^{34}$

To avoid such parallel behavior and its consequent expansion of capital market crises, it seems important to have multiple solvency models. In this context, internal models might play a special role. After being accredited by the supervisory authority, insurers could use an internal risk model for the SST computations and, indeed, the Swiss supervisory authority strongly supports the use of such internal models. ${ }^{35}$ The use of a broad range of internal models most certainly reduces systematic risk in the insurance market. Moreover, internal models are expected to result in more accurate analysis, control, and management of insurers' financial situation than do the more generic standard models.

As mentioned in the section entitled "The SST: an overview", an advantage of the SST in this context is its principle-based concept. Encouraging insurers to use their own volatilities and correlations for certain investments allows for more variety and generally reduces systematic risk. Thus there is less danger of systematic behavior with a principle-based approach than with a rule-based approach.

\section{Effects of risk-based capital standards on liability management}

\section{Corporate finance}

The SST generally leads to higher capital requirements at the corporate level. This increase can be caused by, for example, a higher safety level set by the regulators or by the results of new scenario analyses for estimating liabilities. A field test of the SST in 2005 showed that specific scenario tests can result in a 5-10 percent increase in

\footnotetext{
${ }^{33}$ See Eling et al. (2007).

${ }^{34}$ See Cummins and Doherty (2002, pp. 6-8).

${ }^{35}$ See Federal Office of Private Insurance (2004, p. 29).
} 


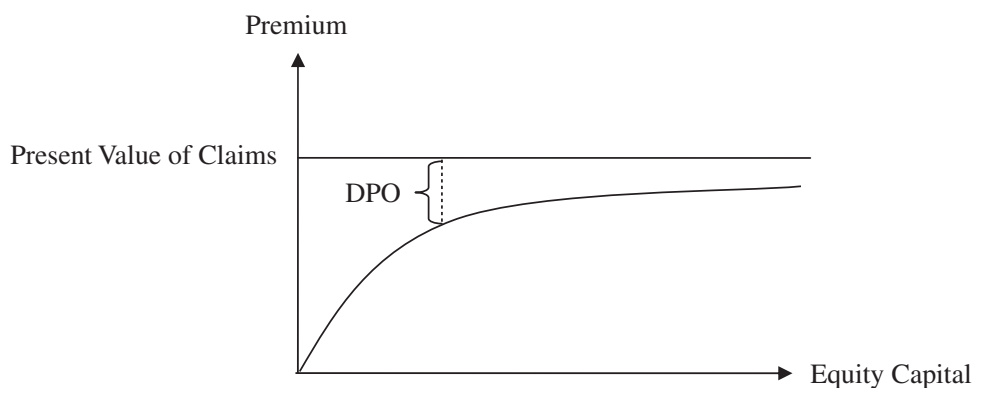

Figure 4. Competitive equity-premium combinations in option pricing model.

expected shortfall. In addition, insufficient diversification, market risks, or insurance risks such as surrender, as well as asset-liability mismatch, can lead to a substantial increase in target capital. The 2005 SST field test revealed that a market-based valuation of assets and liabilities leads to a decrease in the capital adequacy particularly for life insurers - compared to the statutory requirements imposed by Solvency I. ${ }^{36}$ Most probably, target capital requirements derived within Solvency II will cause a similar decrease in an insurer's capital adequacy and hence the considerations in the following discussion may be useful for the ongoing discussion in the EU.

An increase in target capital (e.g., due to a higher safety level) requires implementing risk management measures - for instance, providing more equity capital - which also has the effect of increasing premiums, ${ }^{37}$ as is illustrated in Figure 4.

To increase the safety level, the value of the default put option must be lowered. This induces an increase in equity and premiums. If the actual market premium is already higher than the no-arbitrage price displayed in Figure 4, market premiums will not need to be increased (in this case, earnings decrease). Concerning an increase in equity capital, one needs to take into account that rapid adjustment of equity is usually not possible since capital markets are not completely efficient. In this case, capital costs will be mainly driven by the costs of alternative risk management measures, especially reinsurance. ${ }^{38}$ The issue of reinsurance becomes even more important due to the fact that a full risk transfer by way of reinsurance can reduce the target capital required under the SST. This leads to an increase in underwriting capacities and may change the demand for new and existing reinsurance products. However, the SST also requires insurers to hold capital for credit risk associated with the reinsurance company. Concrete effects will thus depend on the specific integration of reinsurance in the company's risk management plan.

If premiums must be raised due to an increase in the required safety level, policyholders must decide whether they are willing to pay the extra amount.

\footnotetext{
${ }^{36}$ See Federal Office of Private Insurance (2006c).

37 See Doherty and Garven (1986).

${ }^{38}$ See Doherty and Tinic (1981).
} 


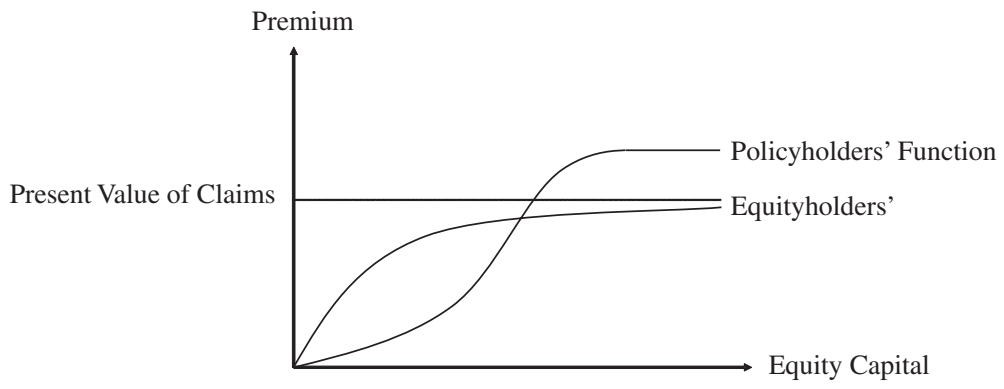

Figure 5. Modified relationship between equity and premium.

Experimental studies ${ }^{39}$ show that the price function of policyholders generally deviates from the option pricing method displayed in Figure 4. Reasons for deviation include inhomogeneous expectations, regulatory effects, taxes, transaction costs, or a differing risk perception. ${ }^{40}$ The latter, in particular, can lead to highly risk-averse behavior and thus to a price function as shown in Figure 5, which reacts very sensitively toward changes in the safety level. Typically, one can observe that policyholders will agree to pay a much higher premium for higher safety levels (which will be communicated through, e.g., rating agencies).

Overall, the effect on corporate financing of an increase in target capital will be moderate since Swiss insurers are generally already sufficiently capitalized either due to the use of their own internal risk models or because of the desire to satisfy rating requirements. ${ }^{41}$ According to FOPI, the solvency ratio (available in percentage of required solvency capital) under Solvency I was 251 percent for life insurers, and 331 percent for non-life insurers at the end of $2006 .{ }^{42}$ The statutory equity, measured as a percentage of business volume, has thus clearly increased (life +16 percent, non-life +10 percent, reinsurance +33 percent), as it did in the previous 3 years. The 2006 field test of the SST showed that, on average, life insurance companies were very well capitalized.

\section{Insurance product design}

Even though the SST may have limited effect at the corporate level, it will likely lead to adjustments in product design for both the life and non-life insurance sectors. Below, we first point out some central properties of the SST that will have an impact on insurance products. We follow this with a closer look at the implications for life and non-life insurance products.

\footnotetext{
${ }^{39}$ See Wakker et al. (1997).

${ }^{40}$ See Gründl and Schmeiser (2002).

${ }^{41}$ Fitch Ratings (2005). Among the 14 supervised life insurers, five have a full or partial internal SST model, as do nine of the 19 supervised non-life insurers, and two of the 13 supervised health insurers (see Federal Office of Private Insurance (2007b, p. 2)).

${ }^{42}$ See Federal Office of Private Insurance (2007a).
} 


\section{Relevant properties of the SST for product design}

The SST explicitly quantifies correlations, volatilities, and scenario analyses for market, insurance, and credit risk. Solvency capital requirements are then determined by aggregating results for normal years and requirements resulting from scenario tests that combine all three types of risk. ${ }^{43}$ The results of the 2006 field test ${ }^{44}$ illustrate that for life insurers, market risk is dominant, while for non-life insurers, insurance risk is most prevalent. For all companies, credit risk ranks third. The risk-based capital calculations within the SST lead to a holistic picture of an insurer's risk situation at the corporate level. On the one hand, risk accumulation and volatility of big losses in individual lines of business are taken into account. On the other hand, the SST recognizes diversification effects through, for example, independent or even negatively correlated risks that serve to reduce solvency capital. Therefore, an insurance portfolio must be considered as a whole, including different lines of business and insurance types, which will lead to an increase in the complexity of risk selection processes.

At the 99 percent confidence level (see the section above on the overview of the SST), the expected shortfall concept is more restrictive than the value-at-risk concept. The 2005 field test ${ }^{45}$ showed that for life (non-life) insurance companies, the weighted average of the 99 percent expected shortfall is approximately 13 percent ( 9 percent) higher than the 99.5 percent value at risk.

Overall, the convergence of necessary regulatory capital and economic capital facilitates product development and appropriate pricing. At the same time, transparency is substantially increased, which enables a well-founded and critical evaluation of costs, profitability, and securitization and thus an efficient assignment of resources and capital.

\section{The effect of the SST on life insurance products}

In recent years, the Swiss life insurance market recorded a slightly declining premium volume. Furthermore, a trend away from traditional endowment life insurance contracts toward unit-linked products has been observed, as displayed in Figure 6.

Unit-linked products provide upside potential due to the investment in a mutual fund, where policyholders bear the main investment risk. Usually, an investment guarantee is given on the premium payments, such as, for example, an interest rate or lookback guarantee. ${ }^{46}$

Another market innovation has been the development of modular products, starting in 2005/2006. This type of product includes only a basic guarantee; all other options are purchased separately as desired, at an appropriate price. For policyholders, these products are thus highly transparent. It can be expected that the SST will intensify this product trend in the medium and long term, accompanied by a reduction of capitalintensive contract components in life insurance policies. Insurers are required to

\footnotetext{
${ }^{43}$ See Federal Office of Private Insurance (2004).

${ }^{44}$ See Federal Office of Private Insurance (2007b).

45 See Federal Office of Private Insurance (2006a, c).

${ }^{46}$ See Grosen and Jørgensen (2000) as well as Gatzert and Schmeiser (2007b) for an analysis of these types of guarantees in unit-linked products under different investment strategies.
} 


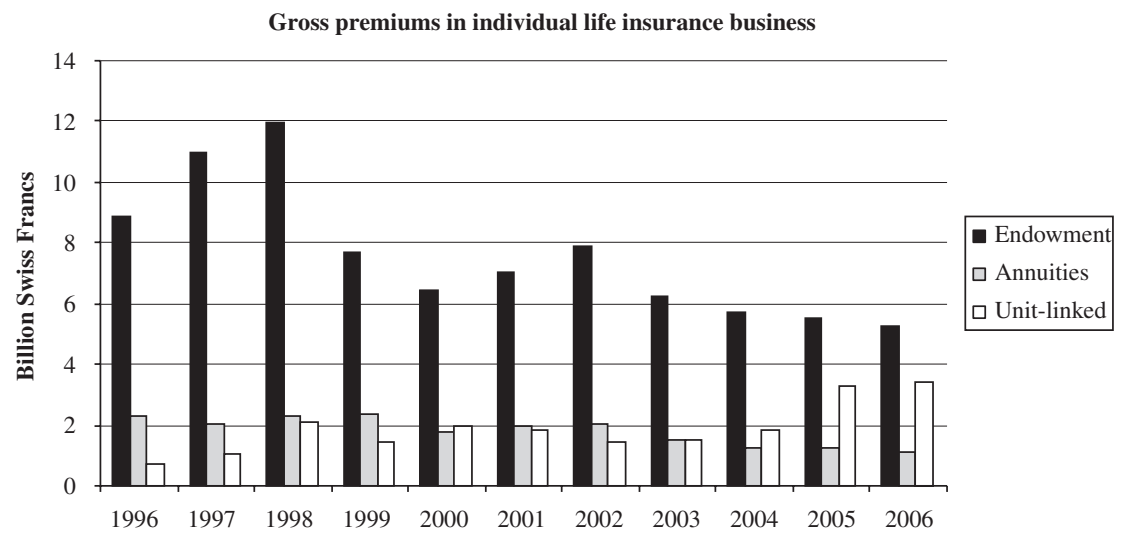

Figure 6. Development of life insurance products in Switzerland.

Data source: Federal Office of Private Insurance "Statistiken 2007," available at www.bpv.admin.ch. Results for 2006 are estimates by the Swiss Insurance Association, available at www.svv.ch.

provide additional capital if assets have a shorter time to maturity than liabilities so as to secure the default risk of guarantees in case of adverse market developments. Since life insurance companies are subject to substantial market risk, the securitization of guarantees and options is quite expensive. This is of particular concern for guarantees and options in long-term products. One serious problem with products having a long time to maturity is unexpected changes in insurance risks during the contract term. In the SST target capital calculations for life insurers, insurance risk includes option exercise, surrender, costs, reactivation, disability, longevity, and mortality. Furthermore, scenarios involving global deflation, longevity, pandemics, invalidity, equity drops, terrorism, and surrender are included, among others. In the case of annuities, for instance, longevity risk (improvement in life expectancy) can pose a serious threat to pension firms if guarantee components cannot be adjusted during the contract term. The 2006 field test showed that for life insurers, the global deflation scenario has the largest impact on the SST solvency ratio (almost 40 percent).

Policies with embedded options such as surrender, paid-up, or switching death benefit, require assumptions about policyholder exercise behavior when estimating liabilities. ${ }^{47}$ Exercise behavior can have a considerable effect on the whole portfolio of insureds if, for example, mostly "good" risks surrender their policies, while "bad" risks remain in the portfolio and increase their death benefits.

The SST requires adequate pricing and recognition of risks associated with products that include embedded options. Thus, the characteristics of life insurance products described above generally lead to an increase in capital requirements. There are several ways to reduce the insurer's risk and thus solvency capital. Embedded options and guarantees can be retained if a "fair" price for the associated risk can be obtained. ${ }^{48}$

\footnotetext{
${ }^{47}$ The paid-up option, for instance, is treated in Kling et al. (2006) and in Gatzert and Schmeiser (2007a).

${ }^{48}$ In this context, the term "fair" (or appropriate) price is used in a financial sense as described in Doherty and Garven (1986).
} 
The modular products discussed above are one means of achieving fair prices for covered risks, with the added advantage of being transparent to the customer. Capital costs for the risks associated with purchased options (those in addition to the basic guarantee as selected by the customer) can then be reduced through securitizing, hedging, diversification, pooling, or reinsurance.

Alternatively, capital-intensive contract components could be excluded from the policy design to avoid high solvency capital costs. Risks can therefore be shifted toward policyholders, as is done in the case of unit-linked products. This design possibility is particularly relevant for traditional participating life insurance contracts, which require a higher solvency capital due to the numerous options and guarantees included in the contracts. An important related aspect is policyholder perception of the value of guarantees and options in life insurance products and their resulting willingness or unwillingness to pay a fair price. Thus, insurers will need to identify capital-intensive product components that impose a substantial risk to the insurer but are not highly desired by policyholders. For instance, instead of including expensive cliquet-style guarantees, point-to-point guarantees can be offered. ${ }^{49}$ In general, a reduction of guarantees and options as a consequence of risk-based capital standards, as well as an intensification of the trend toward unit-linked products, is very likely. ${ }^{50}$

Further, SST-induced risk management mechanisms such as, for example, cash flow matching, may lead to a trend on the asset side toward pure low-risk bond contracts and thus to products having lower risk. This can jeopardize the attractiveness of participating contracts due to a loss of participant autonomy. For instance, participating contracts can be replaced with pure term insurance and a bond portfolio, both of which can be obtained from an investment firm at less cost. Pension funds could be another substitute. These institutions are subject to different regulation, making it possible for them to offer high-risk products without having to meet correspondingly high capital requirements.

Another viable new insurance product could involve allowing the insurer to modify certain provisions during the contract term given the occurrence of certain specified events. For instance, premiums could be adjusted based on the inflation index, or guaranteed rates in annuities could be modified based on an updated life expectancy determination.

\section{The effect of the SST on non-life insurance products}

The SST's effect on non-life insurance products is less pronounced. For this type of insurance, premiums and target capital are based not only on expected loss but also depend on volatility, loss accumulation, and major claim distributions across the different lines of business. Moreover, dependencies in the loss distributions must be taken into account. These considerations imply higher capital requirements for lines of business having higher-than-average volatility, such as property (subject to

\footnotetext{
${ }^{49}$ See, for example, Gatzert and Kling (2007) and Kling et al. (2007) for a comparison of shortfall risk between cliquet-style and point-to-point guarantees.

${ }^{50}$ See also the survey by Fox-Pitt, Kelton (2006).
} 
catastrophes) and liability insurance, as well as credit, aviation liability, and transit insurance. ${ }^{51}$ In this respect, it is crucial not to underestimate risk over the long run. Accurate modeling of individual losses that could involve large claim amounts is especially important, for example property - fire - and liability - product, motorcycle liability. ${ }^{52}$

If an insurer is sufficiently capitalized according to the risk-based capital standards, product diversity can be improved and extended. Otherwise, possible consequences (and actions taken in reaction to them) will be very similar to those faced by the life insurance sector, in particular the exclusion of certain types of risk and a shift of risk onto policyholders. A reduction in volatility could be achieved by, for example, an intensification of retentions and an increasing number of exclusion clauses that fully or partially exempt certain types of risk. In this regard, insurers will need to pay special attention to risks that are difficult to assess and quantify, such as asbestos or terrorism. In addition, one can expect a change in underwriting policy toward less volatile risks manifested by a concentration on target groups with lower expected claims costs and lower volatility, making the insurer less susceptible to accumulation risk. Eliminating or, at least, reducing the importance of highly volatile and nonprofitable segments of the business is made more straightforward by the increased transparency associated with risk-based capital standards. In particular, liability insurance is required to have more solvency capital than was the case before the SST. ${ }^{53}$ Stricter model (internal or standard) scenarios and stress tests can highlight the unattractiveness of certain product lines, thus creating an opportunity to readjust the insurer's risk burden. ${ }^{54}$ In general, if a practice of excluding certain risks reduces business volume, insurance companies will prefer to insure the risks, but at an appropriate price.

Another important effect of the SST on the non-life insurance business has to do with the necessity of considering investment risk when calculating solvency capital. Until the late 1990s, premiums were priced at amounts too low to actually cover claims costs and expenses, on the theory that the shortfall would be made up by returns on investments. However, this practice did not adequately consider the unpredictability of the "real" world and thus, after the financial market crisis of 2001, premium prices had to be increased. Thus, the new requirement to consider investment risk in non-life insurance policies sanctions cash flow underwriting, with the resultant effect of stabilizing price cycles. This premise is supported by model calculations conducted in Baur and Enz. ${ }^{55}$ Their results illustrate that in the year 2000, insurers in the four largest European non-life insurance markets (Germany, France, the United Kingdom, and Italy) would have needed additional solvency capital for their asset portfolios in an amount equal to almost half of their asset base when using the expected shortfall approach, given their stock investments of almost 40 percent. ${ }^{56}$

\footnotetext{
${ }^{51}$ See Baur and Enz (2006).

${ }^{52}$ See Federal Office of Private Insurance (2006b).

${ }^{53}$ See Baur and Enz (2006).

${ }^{54}$ See Federal Office of Private Insurance (2004).

${ }^{55}$ Baur and Enz (2006).

56 Ibid.
} 


\section{Conclusion}

In this paper, we discuss the SST, highlighting its main features and discussing its significant economic implications for the Swiss economy, particularly focusing on capital markets, corporate finance, and product design. These discussed effects can be generalized in principle to other approaches of capital regulation, since they are primarily caused by the transition to risk-based supervision. We believe this aspect to be of particular interest in respect to the ongoing Solvency II process in the European Union.

The new, risk-oriented control of asset management as envisioned by the SST will change the investment policies of insurers and thus have a substantial impact on the capital markets. We thus expect a shift toward long-term bonds and a flat term structure in the Swiss and other European capital markets over the next few years. Similar shifting might occur in the real estate markets, while changes in stock market investment activity are not very likely.

The SST's impact at the corporate level will be rather moderate with respect to corporate financing because Swiss insurers are generally already well capitalized. The SST's recognition of the full risk transfer achieved by reinsurance will lead to reductions in required target capital, accompanied by an increase in demand for reinsurance products, both as they exist now and in regard to new products specifically designed with the SST in mind.

Furthermore, we expect a trend toward modular products in the life insurance industry and, particularly, a reduction of capital-intensive contract components (in particular, embedded options) in long-term products. Sanctioning of cash flow underwriting due to consideration of investment risk in non-life insurance policies will tend to result in a weakening of price cycles. Furthermore, consideration of volatility, susceptibility to major claims, and intensity of accumulated losses will imply higher capital requirements for lines of business with above-average volatility, for example hail or storm insurance.

Our analysis, along with feedback from market participants, leads us to conclude that the risk- and principles-based SST is a flexible and transparent framework based on a realistic economic model. However, as the insurance industry is one of the largest institutional investors in Switzerland, possible changes in asset and liability management will have a noticeable effect on capital market demand and product design. We therefore encourage regulators to carefully monitor the economic implications of the SST during the next several years.

\section{References}

Bank for International Settlements (2006) BIS Quarterly Review (June), Basel: Bank for International Settlements.

Baranoff, E.G., Sager, T.W. and Witt, R.C. (1999) 'Industry segmentation and predictor motifs for solvency analysis of the life/health insurance industry', Journal of Risk and Insurance 66: 99-123.

Barth, M.M. (2000) 'A comparison of risk-based capital standards under the expected policyholder deficit and the probability of ruin approaches', Journal of Risk and Insurance 67: 397-414.

Baur, P. and Enz, R. (2006) 'Solvency II: An integrated risk approach for European insurers', Swiss Re Sigma 4: 1-44. 
Brockett, P.L., Cooper, W.W., Golden, L.L. and Pitaktong, U. (1994) 'A neural network method for obtaining an early warning of insurer insolvency', Journal of Risk and Insurance 61: 402-424.

Browne, M.J., Carson, J.M. and Hoyt, R.E. (1999) 'Economic and market predictors in the life-health insurance industry', Journal of Risk and Insurance 66: 643-659.

Butsic, R.P. (1994) 'Solvency measurement for property-liability risk-based capital applications', Journal of Risk and Insurance 61: 656-690.

Carson, J.M. and Hoyt, R.E. (1995) 'Life insurer financial distress: Classification models and empirical evidence', Journal of Risk and Insurance 62: 764-775.

Chen, R. and Wong, K.A. (2004) 'The determinants of financial health of Asian insurance companies', Journal of Risk and Insurance 71: 469-499.

Cummins, J.D. and Doherty, N.A. (2002) 'Capitalization of the property-liability insurance industry: Overview', Journal of Financial Services Research 21: 5-14.

Cummins, J.D., Grace, M. and Phillips, R.D. (1999) 'Regulatory solvency prediction in property-liability insurance: Risk-based capital, audit ratios, and cash flow simulation', Journal of Risk and Insurance 66: 417-458.

Cummins, J.D., Harrington, S. and Klein, R.W. (1995) 'Insolvency experience, risk-based capital, and prompt corrective action in property-liability insurance', Journal of Banking and Finance 19: 511-527.

Cummins, J.D. and Rubio-Misas, M. (2006) 'Deregulation, consolidation, and efficiency: Evidence from the Spanish insurance industry', Journal of Money, Credit, and Banking 38: 323-356.

Doherty, N.A. and Garven, J.R. (1986) 'Price regulation in property-liability insurance: A contingent-claims approach', Journal of Finance 41: 1031-1050.

Doherty, N.A. and Tinic, S.M. (1981) 'Reinsurance under conditions of capital market equilibrium: A note', Journal of Finance 36: 149-153.

Eling, M., Schmeiser, H. and Schmit, J.T. (2007) 'The solvency II process: Overview and critical analysis', Risk Management and Insurance Review 10: 69-85.

European Actuarial Consultative Group (2004) Solvency II-Groupe Consultatif Response to MARKT/2543/ 03, available at www.gcactuaries.org.

Federal Office of Private Insurance (FOPI) (2004) White Paper of the Swiss Solvency Test, Bern: FOPI.

Federal Office of Private Insurance (FOPI) (2006a) Jahresbericht 2005, Bern: FOPI.

Federal Office of Private Insurance (FOPI) (2006b) Technisches Dokument zum Swiss Solvency Test, Bern: FOPI.

Federal Office of Private Insurance (FOPI) (2006c) Swiss Solvency Test: Preliminary-Analysis Field Test 2005, presentation 13.01.2006, available at www.bpv.admin.ch.

Federal Office of Private Insurance (FOPI) (2007a) Versicherungsmarkt 2006: Verbesserung der Solvenz, available at www.bpv.admin.ch.

Federal Office of Private Insurance (FOPI) (2007b) Swiss Solvency Test Field Test 2006, presentation 07.08.2007, available at www.bpv.admin.ch.

Financial Services Authority (FSA) (2007) Principles-Based Regulation - Focusing on the Outcomes that Matter, available on http://www.fsa.gov.uk.

Fitch Ratings (2005) Solvency II - What is Happening?, Europe Special Report, New York: Fitch Ratings.

Fox-Pitt, Kelton (2006) European Insurance - Solvency II: The Invisible Force, Chicago: Fox-Pitt, Kelton.

Gatzert, N. and Kling, A. (2007) 'Analysis of participating life insurance contracts: A unification approach', Journal of Risk and Insurance 74: 547-570.

Gatzert, N. and Schmeiser, H. (2007a) Assessing the risk potential of premium payment options in participating life insurance contracts, Working Paper on Risk Management and Insurance, University of St. Gallen, forthcoming in Journal of Risk and Insurance.

Gatzert, N. and Schmeiser, H. (2007b) Investment guarantees in unit-linked life insurance products: Comparing cost and performance, Working Paper on Risk Management and Insurance, University of St. Gallen.

Grace, M., Harrington, S. and Klein, R.W. (1998) 'Risk-based capital and solvency screening in propertyliability insurance', Journal of Risk and Insurance 65: 213-243.

Grosen, A. and Jørgensen, P.L. (2000) 'Fair valuation of life insurance liabilities: The impact of interest rate guarantees, surrender options, and bonus policies', Insurance: Mathematics and Economics 26: $37-57$. 
Gründl, H. and Schmeiser, H. (2002) 'Marktwertorientierte Unternehmens- und Geschäftsbereichssteuerung in Finanzdienstleistungsunternehmen', Zeitschrift für Betriebswirtschaft 72: 797-822.

Grunert, J., Kleff, V., Norden, L. and Weber, M. (2002) 'Mittelstand und Basel II: Der Einfluss der neuen Eigentkapitalvereinbarung für Banken auf die Kalkulation von Kreditzinsen', Zeitschrift für Betriebswirtschaft 72: 1045-1064.

Huesler, R.P. (2006) 'Investieren mit striktem Blick auf die Passivseite', Schweizer Versicherung 19: 24-26.

Informations- und Ausbildungszentrum für Immobilien (2006) Newsletter (April), Bülach.

Kling, A., Richter, A. and Ruß, J. (2007) 'The interaction of guarantees, surplus distribution, and asset allocation in with profit life insurance policies', Insurance: Mathematics and Economics 40: 164-178.

Kling, A., Ruß, J. and Schmeiser, H. (2006) 'Analysis of embedded options in individual pension schemes in Germany', The Geneva Risk and Insurance Review 31: 43-60.

Luder, T. (2005) Swiss Solvency Test in Non-life Insurance, paper presented at the 36th ASTIN Colloquium 2005, Zurich.

Miles, D. and Baker, M. (2005) Real Yields, Pensions and Shifts in Demand for Bonds (July), London: Morgan Stanley Equity Research Europe.

Munch, P. and Smallwood, D.E. (1981) 'Theory of solvency regulation in the property and casualty insurance industry', in G. Fromm (ed) Studies in Public Regulation, Cambridge, MA: The MIT Press, pp. 119-180.

Pottier, S. and Sommer, D. (2002) 'The effectiveness of public and private sector summary risk measures in predicting insurer insolvencies', Journal of Financial Services Research 21: 101-116.

Reitz, U. and Stocker, F. (2005) '50jährige Bundesanleihe in der Kritik', Welt am Sonntag 58(3 April): 37. Sandström, A. (2006) Solvency, Boca Raton, FL: Chapman \& Hall/CRC.

Schmeiser, H., Eling, M., Gatzert, N., Schuckmann, S. and Tolek, D. (2006) Volkswirtschaftliche Implikationen des Swiss Solvency Tests, VW Schriftenreihe Band 48, St. Gallen: Institut für Versicherungswirtschaft.

Swiss Insurance Association (2006) Facts and Figures 2006, Zürich: Swiss Insurance Association.

Van Rossum, A. (2005) 'Regulation and insurance economics', The Geneva Papers on Risk and Insurance Issues and Practice 30: 156-177.

Wakker, P.P., Thaler, R.H. and Tversky, A. (1997) 'Probabilistic insurance', Journal of Risk and Uncertainty 15: $7-28$.

\section{About the Authors}

Martin Eling is a post-doctoral research fellow at the University of St. Gallen, Switzerland, and currently visiting professor at the University of Wisconsin-Madison. $\mathrm{He}$ received his doctoral degree from the University of Münster, Germany. His research interests include asset-liability management, empirical finance, and enterprise risk management. He has published articles in numerous peer-reviewed journals such as the Journal of Banking \& Finance, Financial Analysts Journal, and Risk Management \& Insurance Review.

Nadine Gatzert is a postdoctoral research fellow and project manager at the Institute of Insurance Economics of the University of St. Gallen, Switzerland. She studied mathematics and economics at the University of Ulm, Germany, and at the University of Southern California in Los Angeles, U.S.A., majoring in mathematical finance and actuarial science, and received her doctoral degree from the University of St. Gallen, Switzerland. Her research interests include asset-liability management, alternative risk transfer, and embedded options in life insurance contracts. She has published articles in peer-reviewed journals such as the Journal of Risk and Insurance, Insurance: Mathematics and Economics, and Financial Markets and Portfolio Management. 
Hato Schmeiser studied business administration at the University of Mannheim, Germany. After his doctoral degree and the postdoctoral lecture qualification (Habilitation) in 2003 (Humboldt-Universität zu Berlin), he was appointed Professor for Insurance and Risk Management at the University of Münster. Since 2005, he is Chair for Risk Management and Insurance at the University of St.Gallen. His main research interests include individual financial planning, dynamic financial analysis, option pricing, and regulation of financial firms. 